\title{
The Change of Time and Space in E-Learning
}

\author{
Anne Mette Nortvig* \\ Departmentof Learning and Philosophy, Aalborg University, Copenhagen, Denmark \\ *Corresponding author: amn@learning.aau.dk \\ Received July 09, 2014; Revised July 25, 2014; Accepted July 29, 2014
}

\begin{abstract}
Teaching in e-learning settings often involves the dichotomies of time (synchronous/asynchronous) and space (same place/different places), but when e-learning involves a hybrid mix of students on campus and e-learning students on-line - and the teaching is recorded in order to be watched by other students later on - this traditional dichotomy cannot capture the complex and multiplied learning settings. This paper attempts to focus on the change of space and time in e-learning settings the way e-learning students and teachers in a professional bachelor programin physiotherapy describe it, and the purpose is to present a framework for categorizing time and space in elearning settings. Thus, the paper introduces the concept of multi- and mono-locality in order to be able to describe a teaching and learning settings where presence is sometimes felt in more than one place at a time.
\end{abstract}

Keywords: e-learning, time, space, physiotherapy education, multi- and mono-local settings

Cite This Article: Anne Mette Nortvig, “The Change of Time and Space in E-Learning.” American Journal of Educational Research, vol. 2, no. 8 (2014): 612-616. doi: 10.12691/education-2-8-9.

\section{Introduction}

In certain circumstances, it can be difficult to find a precise answer to the question 'Where are you?' The answer, 'I'm in the classroom', can be as correct as 'I'm on Facebook' because the question can be concerned with both physical and virtual presence. Thus, not only can presence be understood as a physical body in a room, it can also be a virtual and digitally embedded action on-line. Both forms of presence should be taken into consideration in connection with e-learning, because students can be sitting in the classroom but be virtually present elsewhere. Similarly, they can be physically absent although present in the classroom via video conference, and it is therefore necessary to find ways to analyze and create learning designs that take account of both the physical and the virtual presence in this hybrid e-learning settings [1,2,3].

Teaching has traditionally been located within time schedules. Classes take place, for example, between 8:00 A.M. and 2:00 P.M., breaks last 15 minutes, exams are to be held by a certain date, and so on. However, this traditional academic understanding of time as a way of structuring teaching has changed with the adoption of elearning. Because of digital technology and the Internet, teaching and learning can take place at any time, and the student has constant access to teaching from any place $[4,5]$. Moreover, the student usually has the opportunity to decide when he or she wants to learn and according to what rhythm [6] and although a virtual presence differ from a physical one, the students and the teacher can be present at more places at once [7].

The learning outcome of e-learning is sometimes found to be related to the feeling of belonging in the class and the opportunity of ease of contact with the teacher [8]. An experience of social presence among teachers and students is more easily established in e-learning when the learning design is focused on shared time in synchronous teaching or counselling [9] and asynchronous and synchronous elearning is sometimes compared to the different modalities of written and oral communication [4]. Notwithstanding, some research find that the social part of e-learning has little to do with the outcome [10] and a lot to do with the general satisfaction and motivation to learn from elearning courses. However, as cloud-based, mobile and Web 2.0 tools constantly develop, the distinction between the two times appears to be vanishing $[9,11]$. With elearning technology, teaching can take place everywhere, and mixes between physical and virtual spaces become possible [3,12].

Thus, in e-learning settings, the teacher's academic identity is found to be changing [13], and although teachers might not be quite ready to embrace the 'disembodiment' or 're-positioning' required by elearning [14], some suggest that they have to become accustomed to '(dis)embodiment' in order to deepen their understanding of student learning in e-learning settings [15] and emphasis should be devoted to developing the multi-media literacy of teachers and to an awareness of the non-neutral influence of e-learning on both time, space and teaching process in general [16].

All these aspects are very much at stake in the hybrid elearning settings, and the research question in this paper therefore discusses how teachers and students interpret and react to the changing time and space of e-learning.

\subsection{Case Study}

The empirical data in this paper stems from a case study as part of a $\mathrm{PhD}$ project in a physiotherapy education when e-learning was just introduced for the first time in the program in 2011. 
In the beginning, the e-learning design consisted of broadcasted on-campus lectures that could be watched by the e-learning students at home on line or in a recorded and slightly edited version later on. Thus, the e-learning students could choose to participate synchronously in the lecture while it was being recorded, or they could choose to view the video-recorded lecture asynchronously afterwards, i.e., after it had been edited by the teacher.

Thus, the blended/e-learning setting was designed to consist of a mix of on-campus and on-line teaching. In the on-campus part of the teaching, both e-learning students and on-campus students were physically present in the classroom while the other half of the blended learning design consisted of on-campus lectures that were broadcasted so the e-learning students had access to the teaching via the Adobe Connect desktop videoconference system. Over three days, every second week, e-learning students participated in the practical and manual courses on campus; the remaining days consisted of on-line learning (in videoconferences), group work or selfdirected studies.

In the physiotherapy case, e-learning is understood as the component of teaching that takes place when students are away from campus and studying at home. E-learning is thus considered one component of the blended learning design [16]; the other component is the 'traditional' oncampus teaching. This understanding of e-learning is close to Laurillard's definition that sees e-learning as the use of any digital technology or applications in the service of learning $[17,18]$. The definitions of e-learning and technology-enhanced learning therefore overlap in the case.

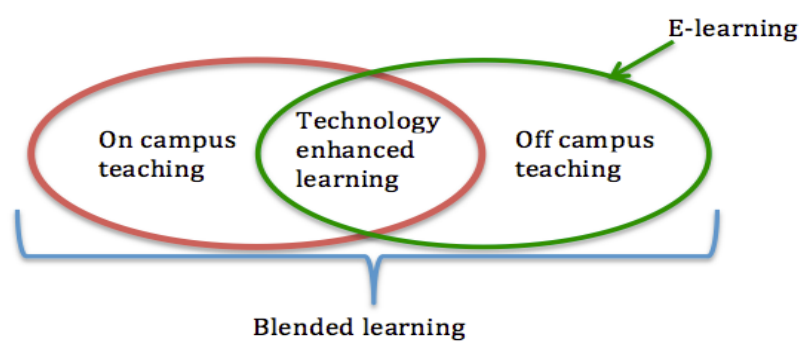

Figure 1. illustrates the way in which blended learning and e-learning are understood and designed in the physiotherapy case.

\section{Methodology and Data Construction}

In the case study, data were constructed with a pragmatic Design-based Research framework [19,20,21] and through Grounded Theory inspired methods $[22,23,24]$, whereas the ontological and epistemological background was found in Symbolic Interactionism [25,26,28]. With the Design-based Research framework the goal was not only to describe the e-learning context as it looked in the beginning but also to create learning designs in collaboration with the students and teachers in the context and to generate theory on this basis $[29,30]$. Therefore, it focused on understanding and describing the new social worlds [31] that emerged because of the changing situation caused by e-learning. Resistance and/or interest towards e-learning and preoccupation with changing the current learning designs provided important data to these descriptions.
Design-based Research can be defined as a systematic but flexible methodology aimed to improve educational practice through iterative analysis, design, development and implementation. It is based on collaboration among researcher and practitioners in real-world settings, and it aims at generating contextually-sensitive design principles and theories [32]. Thus, guided by the theory generation methodology from Grounded Theory [24], data was constantly compared to data, codes evolved and they were re-compared to data. Categories were built on this basis $[33,34]$ and they grounded the theoretical foundation from Symbolic Interactionism [35]. In order to understand and describe the new social worlds that emerged when elearning was introduced and evolved, focus was set on interactions, meanings and interpretations of e-learning and learning designs in an education with strong traditions for physical presence.

Thus, the qualitative data were constructed though interviews, workshops and participant observation of the teaching on campus and on-line [36,37]. The participant observation phases lasted 8 weeks during the first year and 2 weeks in the second year, and the interviews and workshop took place in between these phases over a period of 21 months. 5 focus groups were conducted with 4-9 e-learning students in each group, one focus group with a mix of 5 students and 2 clinical teachers and 5 semi-structured interviews with the teachers took place in relation to the teaching; they all concerned e-learning, learning design and professional identity formation in elearning physiotherapy education. Finally, in order to compare the e-learning students' and the on campus students' views upon learning outcome in relation to different learning settings, a survey among the physiotherapy students was conducted the second year.

\section{Findings and Discussion}

On the basis of these empirical data, the findings that formed the point of departure for the design experiments that took place later on in the project ${ }^{1}$ [38]will be presented below. The more poignant quotes from the interviews are selected in order to illustrate the setting from both the students' and the teachers' perspective.

\subsection{A Teacher Perspective on E-Learning}

From the teacher's perspective, the classroom consisted of a group of students of which he or she could only see the faces - and bodies - of those students who were physically present. The e-learning students appeared on the computer screen as names and green dots. However, the teacher was very aware of the presence of both groups in the classroom but expressed and showed difficulty in including both groups in the teaching simultaneously. During the participant observation in the on-line physiotherapy lectures, the teachers rarely spoke directly to the e-learning students. A teacher explained it like this:

'I don't communicate with them [the e-learning students at home] using my face because it would take the focus away from the students sitting there [in the classroom]... But I am very aware of them, that they don't

1 These experiments are not presented in this paper but they are discussed in Nortvig, 2014 
feel like they are just sitting on the side-lines.' (Teacher interview)

In the beginning, the camera was placed beside the teacher in order not to overly disturb the teaching, and although it was directly in front of the teacher later on, his or her focus was mainly on the on-campus students. Usually, before and after the lecture or during breaks, the teachers addressed the e-students in the chat to verify whether the technology functioned as anticipated, or whether they had questions relating to the content of the hour-long lectures but they very rarely did so during the lecture.

'You really need big reserves of energy to be present both in the classroom with the students and pay attention to the chat and to respond to the e-learning students without making the on-campus students think: 'Well, now I'm just wasting my time...' So I think it's really difficult to be synchronously present virtually and in the classroom; I haven't been able to do it.' (Teacher interview)

The teachers found this doubled presence difficult and the following experience was very common:

'It's damn hard! You live in two worlds!' (Teacher interview)

The teachers' experiences of living in two worlds at the same time can be seen as the emergence of a new social sub-world (31), a world setting where people, sometimes, can be present in more places at the same time. The teachers had a preference for being present and teaching in the same physical space as that of students. They argued that physiotherapy is about the body and that a physiotherapist has to know, for example, how to be physically grounded and they sometimes questioned the meaning of relating e-learning to physiotherapy education:

'You cannot learn how a patient's muscle feel by looking at it on a computer screen!'

'You don't have virtual gloves, do you?!'

'You have to be present to touch an elbow, right?'

The e-learning sub-world was therefore often seen from the teacher perspective as a less authentic world compared to the traditional physical space for physiotherapy teaching. However, as e-learning had become a fact in physiotherapy education, the teachers were eager to create learning designs that took a point of departure in the new world's setting and to involve the students' bodies in the learning in others ways than they had done before.

\subsection{A Student Perspective on E-Learning}

Although the teachers saw the traditional single physical space as amore authentic setting for teaching and learning, a lot of the e-learning students found the elearning sub-world to be as authentic as the traditional one. They clearly appreciated the opportunity to be present on social media while they were in class, to check their emails while listening to the lecture and to integrate different digital workspaces into their group work or individual work when they needed a break, or when the lecture was too long etc. They saw the doubled space as a place for both relaxation and work. Some of them expressed the wish that the e-learning were designed to take advantage of these opportunities:

'Group work can be organized so that you shift between on-line activities and physical meetings. But we're supposed to find out ourselves.'
'But in the future, this will be the normal way to teach. It just causes problems now because its in the beginning' (Students in focus group)

The students appreciated the sheer volume of relevant learning content that is already produced and shared by other doctors and physiotherapists, but they also found that they needed help in judging the value and relevance of it:

'I think that there is already a lot on the Internet - that you can just google - about knees and hips and different kinds of training. You just need the knowledge to distinguish whether it's valid research and so on.' (Student in focus group)

This made them discuss the role of the teacher in elearning $[13,14,16]$ and the need of guidance and mediation between what some of them considered as two very different domains in physiotherapy, i.e., the theoretical approach and the physical practice:

'But without a lot of practice, you can end up thinking 'Damn, I'm good at this!' But in fact, you really stink... How could you know?' (Student, focus group)

Thus, the students saw e-learning not only as access to the classroom, but - because of the Internet and the physiotherapy-relevant content that can easily be found they also considered digital technology as enabling access to a big world of physiotherapy and physiotherapists in general and of opportunities of both relaxation, collaboration and work.

\subsection{E-Learning in Multi-Local and Mono- Local Settings}

The way e-learning was referred to in the physiotherapy case showed a need to define and conceptualize the experience that the teachers describe is at stake in the hybrid synchronous classroom. Thus, in order to describe a setting where teachers and/or students are present in more physical and virtual spaces at a time versus settings that include the learners and/or teachers in the same virtual or physical space, the concepts of multi-local and mono-local learning designs were created.

When these concepts were applied, e-learning designs could be divided into synchronous mono-local, synchronous multi-local, asynchronous mono-local and synchronous multi-local ones. Examples of these will follow below.

In the physiotherapy case, the on-campus teaching and the clinical placement could be categorized as mono-local synchronous learning design. In these settings, the teacher and all the students were together at the same time and place; the teacher could frame the situations as traditional physiotherapy teaching where the role of the teacher was known, the activities were chosen by the teacher, and they could easily shift between activities relating to theory or practice. The teachers and the students appreciated this mono-local synchronous setting especially because it resembled the one in which students would live and work as qualified physiotherapists. Moreover, during clinical placement, the students could therefore see themselves as (peripheral) members of the physiotherapists' community of practice $[39,40]$.

The hybrid classroom where the teacher was present in more spaces than just the on-campus classroom, and the elearning students were present both at home and on- 
campus via Adobe Connect was categorized as multilocalsynchronous setting. Accordingly, when all the students were in the classroom, the learning setting could also be multi-local; when the students were present on social media while the teacher was lecturing, they too found themselves in multi-local settings, but contrary to the teacher, many of them liked the multi-local setting and specifically chose to be present here.

When the e-learning setting had been tested for some months, the teachers started to record the lectures in order to enable the e-learning students to view them later, and thereby contributing to the experience of the flexibility in e-learning education, and this way of receiving the lectures was very appreciated among e-learning students. However, in the edition and design of the video recorded lectures, the multi-local synchronous learning setting was turned into an mono-local asynchronous one: in the editing process, the teacher had only the e-learning students in mind and thus he or she could concentrate on being present now only to them. He or she could cut out classroom discussion, questions and group work and could chose to apply extra assignments, information or special questions and exercises for that specific group to be worked with at a chosen time.

The last category of learning design relating to time and space in the physiotherapy case was the multi-local asynchronous setting. This setting was not very common in the case study, and it was usually created by the students in their self-directed studies. It consisted of their work and presence in several physical and virtual spaces across time, and according to an e-learning student in a focus group it helped them both learn and remember:

'When you're used to a lot of media, it's just nice when it all works together... I'm very visually oriented, so I like to take pictures, video clips or film, and then I put it on my blog. Then I remember it better. I learn it better.'

A teacher commented on this use of different technologies in education:

'Not all physiotherapist students learn the same way, for example, not all of them always need to have to touch it to learn it - and digital technology creates opportunities for individuality [...] It seems like the students make very conscious choices in selecting the digital tools they want to use. It looks like they do what is best for them.'

\subsection{Student Evaluation of the Settings}

The students in the physiotherapy case were asked to complete a small on line survey on e-learning and professional education as physiotherapists in general. All e-students and their parallel on-campus classes, $\mathrm{N}=55$, were exposed to the questionnaire, and 31 of them (16 elearning students and 15 on-campus students) completed it. Among them, 14 e-learning students out of 16 always or often watched the recorded version of the lecture, and two only watched them sometimes (1 of these 2 respondents always participated in the online sessions). Among the oncampus students, 4 of the 15 respondents watched the recordings sometimes.

Only 3 out of 16 of the e-learning students always or often participated in the multi-local synchronous teaching in on-line videoconferences, 10 did it sometimes, and 3 chose never to do so.

The e-learning students found that they needed to be very disciplined to be able to study independently; butwhen they were, they found it very rewarding in relation to both freedom, flexibility and learning outcome. They also felt that this opportunity of independency and self-directed studies was valuable to them as future physiotherapists. On a 5-point Likert-scale [41] in the questionnaire, the students were asked the question: 'What do you think contributes more to your education as a physiotherapist?' Their answers are listed below:

Table 1

\begin{tabular}{|c|c|c|}
\hline & $\begin{array}{c}\text { E-learning } \\
\text { students }\end{array}$ & $\begin{array}{c}\text { On campus } \\
\text { students }\end{array}$ \\
\hline Practice-based teaching & 4.4 & 4.8 \\
\hline Clinical placement & 4.3 & 4.8 \\
\hline Collaboration in study groups & 3.5 & 3,4 \\
\hline Lectures on theory & 3.9 & 4.2 \\
\hline Self-studies & 4.0 & 3.5 \\
\hline Work & 2.8 & 1.6 \\
\hline Books and articles & 3.8 & 3.3 \\
\hline The Internet & 3.5 & 3.4 \\
\hline Former experiences & 3.1 & 2.7 \\
\hline
\end{tabular}

Although the two groups' responses are close, when comparisons are made between them and their answers are read together, they point in the same direction: the oncampus students were more likely to value the contribution of mono-local synchronous learning designs - such as clinical placement and theory and practice based teaching on campus - higher than the e-learning students did. Although these e-learning students saw professional contributions in mono-local learning designs, they also indicated that individual studies, former experiences - and thus potential multi-local self-directed learning designs contributed more towards their education as physiotherapists than the on-campus students expressed they did.

\section{Conclusions}

Because e-learning and digital technology expanded and changed the way time and space were understood in the case, it was necessary to develop concepts to describe the e-learning designs that took place and involved presences and activities in e.g. more virtual and/or physical places at the same time. With the concepts of multi-local and mono-local learning settings and designs, this was possible. Moreover, these concepts put an emphasis on the different challenges and opportunities that faced students and teachers when new e-learning designs were to be created in the diverse settings. Not only did e-learning create a new social sub-world of interacting students who studied and made their presence known in other ways than the on-campus students did, it also multiplied the spaces in the on-campus classroom, and thereby created opportunities for learning to take place in multi-local settings. In the case study however, the multilocal settings were predominantly designed actively by the students in their self-directed studies or as a supplementary social space linked to the on-campus classroom.

The teachers carried out several experiments during the first two years of e-learning in the physiotherapy program. One common feature was that they were more interested in creating technological enhanced mono-local learning 
designs even when the setting was multi-local at the outset. Thus, when the multi-local synchronous setting was turned into a mono-local one, the teacher could focus on one group of students at a time. From the perspective of the e-learning students, this had a supplementary sideeffect: the transformation of the multi-local synchronous setting into an mono-local and asynchronous one afforded them more freedom, flexibility and opportunities to design for their own multi-local setting and social presence which, to them, represented some of the core values of e-learning.

As literature reviews state that videoconferencing in relation to education in under-researched, and that the use of videoconferences often tend to stick to the image of "one-to-many" communication [7,42], more experiments and research in this field is needed in order to further explore the changed times and spaces of videoconferences and e-learning in general, and to design time crossing bridges between the physical and virtual worlds.

\section{Acknowledgement}

I wish to thank the teachers and students at the School of Physiotherapy, University College Zealand for their participation and engaged collaboration.

\section{References}

[1] Loureiro - Koechlin C, Allan B. Time, space and structure in an $\mathrm{e}$ - learning and e-mentoringproject. British Journal of Educational Technology 2010; 41(5):721-735.

[2] Giesbers B, Rienties B, Tempelaar D, Gijselaers W. A dynamicanalysis of the interplaybetweenasynchronous and synchronouscommunication in online learning: The impact of motivation. J Comput Assisted Learn 2013.

[3] James N, Busher H. Researching hybrid learningcommunities in the digital age througheducationalethnography. Ethnography and Education 2013; 8(2):194-209.

[4] Garrison DR. E-learning in the 21stcentury: A framework for research and practice. : Taylor \& Francis; 2011.

[5] Harasim LM. Learning theory and online technology. New York, NY: Routledge; 2011.

[6] A theoretical framework for designing online master communities of practice. Forth International Networked Learning Conference (NLC2004); 2004.

[7] Friesen N. Telepresence and Tele-absence: A Phenomenology of the (In) visible Alien Online. Phenomenology\&Practice 2014; 8(1): 17-31.

[8] Hartman J, Truman-Davis B. Factors relating to the satisfaction of facultyteaching online courses at the University of Central Florida. Online education 2001; 2: 109-128.

[9] Tait A. Face-to-face and at a distance: the mediation of guidance and counsellingthrough the new technologies. British Journal of Guidance and Counselling 1999; 27(1): 113-122.

[10] Borup J, West RE, Graham CR. Improving online social presencethroughasynchronous video. The Internet and Higher Education 2012; 15(3): 195-203.

[11] Hedberg JG, Stevenson M. BreakingAway from Text, Time and Place. Curriculum Models for the 21st Century: Springer; 2014. p. 17-33.

[12] Joint Information Systems Committee (JISC). In theirownwords: Exploring the learner'sperspective on e-learning.: Joint Information Systems Committee; 2007.

[13] Hanson J. Displaced but not replaced: the impact of e-learning on academicidentities in highereducation. Teaching in Higher Education 2009; 14(5): 553-564.

[14] Hilary Spencer. A matter of trust and identity: someuniversityteachers'responses to the increaseduse of information technology in theirworkingenvironmentUCL (University College London); 2011.

[15] Taylor PG, Lopez L, Quadrelli C. Flexibility, technology and academics' practices: Tantalising tales and muddymaps. : Citeseer; 1996.

[16] Sappey J, Relf S. Digital Technology Education and ItsImpact on Traditional Academic Roles and Practice. Journal of University Teaching and Learning Practice 2010; 7(1): 3.

[17] Graham CR, Dzuiban C. Blended learningenvironments. In: Spector JM, Merrill MD, van Merriënboer J, Driscoll MP, editors. Handbook of Research on Educational Communications and Technology New York: Routledge; 2008. p. 269-276.

[18] Laurillard D. E-learning in highereducation. Changinghighereducation: The development of learning and teaching 2006: 71-84.

[19] Amiel T, Reeves TC. Design-Based Research and Educational Technology: Rethinking Technology and the Research Agenda. Journal of Educational Technology \& Society 2008; 11(4).

[20] Anderson T, Shattuck J. Design-Based Research A Decade of Progress in Education Research? Educational Researcher 2012; 41(1): 16-25.

[21] Brown AL. Design experiments: Theoretical and methodologicalchallenges in creatingcomplex interventions in classroomsettings. The journal of the learningsciences 1992; 2(2): 141-178.

[22] Charmaz K. Constructing grounded theory: A practical guide throughqualitativeanalysis. London: Sage; 2006.

[23] Clarke A. Situationalanalysis: Grounded theoryafter the postmodernturn. London: Sage; 2005.

[24] Charmaz K. Grounded theory. Strategies of qualitativeinquiry 2003; 2: 249.

[25] Blumer H. Symbolicinteractionism: Perspective and method. London: University of California Pr; 1969.

[26] Reynolds LT, Herman-Kinney NJ. Handbook of symbolicinteractionism. Oxford: RowmanAltamira; 2003.

[27] Denzin NK. 40th Anniversary of Studies in SymbolicInteraction. : Emerald Group Publishing; 2013.

[28] Mead GH. Mind, self, and society: From the standpoint of a social behaviorist. London: University of Chicago press; 1934.

[29] Dede C. If design-based research is the answer, what is the question? A commentary on Collins, Joseph, and Bielaczyc; diSessa and Cobb; and Fishman, Marx, Blumenthal, Krajcik, and Soloway in the JLSspecialissue on design-based research. The Journal of the Learning Sciences 2004; 13(1): 105-114.

[30] Edelson DC. Design research: Whatwelearnwhenweengage in design. The Journal of the Learning sciences 2002; 11(1): 105-121.

[31] Strauss AL. A social worldsperspective. Studies in symbolicinteraction 1978; 1: 119-128.

[32] Wang F, Hannafin MJ. Design-based research and technologyenhancedlearningenvironments. Educational Technology Research and Development 2005; 53(4): 5-23.

[33] Charmaz K. Grounded Theory. In: Smith JA, Harré R, Van Langenhove L, editors. Rethinkingmethods in psychology London: Sage; 1995. p. 27-49.

[34] Glaser B, Strauss AL. The Discovery of Grounded Theory: Strategies for Qualitative Research. New York: Aldine Publishing Co.; 1967.

[35] Clarke A. From Grounded Theory to Situational Analysis: What's new? Why? How? Developing grounded theory: The second generation 2009: 194-234.

[36] CreswellJW, Clark VLP. Designing and conducting mixed methods research. : Wiley Online Library; 2007.

[37] Hine C. Virtual Research Methods. London: SAGE Publications; 2013.

[38] Nortvig A. E-learning in poly-topicsettings. Electronic Journal of e-Learning 2014; 12(2): 206-214.

[39] Wenger E. Communities of practice: Learning, meaning, and identity. New York: Cambridge university press; 1998.

[40] Lave J, Wenger E. Situatedknowledge and legitimateperipherical participation. New York: Cambridge University Press; 1991.

[41] Bryman A. Social research methods. Oxford: Oxford university press; 2012.

[42] Lawson T, Comber C, Gage J, Cullum - Hanshaw A. Images of the future for education? Videoconferencing: A literature review. Technology, Pedagogy and Education 2010; 19(3): 295-314. 